\title{
Projeto do Código Civil - A Importância das Cláusulas Gerais na Regulação do Direito Pessoal e
Patrimonial de Família'
}

Eduardo Ofilva da Oilua

Mestrando em Direito na Universidade Federal do Rio Grande do Sul - UFRGS

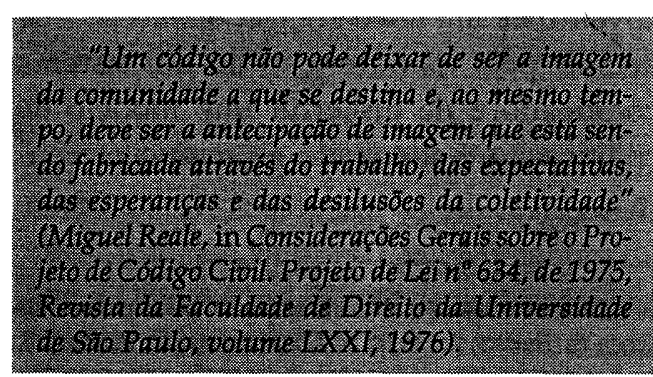

\section{SUMÁRIO}

Introdução.

Parte I - Estrutura do Direito de Familia no Projeto do Código Civil:

A) Direito pessoal e patrimonial de familia;

B) Cláusula geral da comunhão plena de vida e suas repercussões.

Parte II - Elementos de cisão e ressistematização do Direito de Família:

A) O Direito de Família como um modelo aberto;

B) Inter-relações sistêmicas. Apontamentos conclusivos.

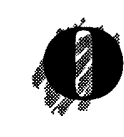

tema que iremos abordar revestese de especial importância em face da votação, pelo Senado Federal, do Projeto de Código Civil em tramitação desde $1975 .{ }^{2}$ No que concerne especificamente ao Direito de Família, sua elaboração, de ares inovadores e ousados para época, garante ainda hoje surpreendente atualidade em comparação aos mais modernos ordenamentos jurídicos contemporâneos e a permanente evolução cultural acerca des. ta matéria. Da lavra do Professor Clóvis do Couto e Silva, falecido em 1992, Professor Catedrático de Direito Civil da Universidade Federal do Rio Grande do Sul, civilista reconhecido internacionalmente por sua visão peculiar do Direito, o livro de Direito de Família pôde auto-renovar-se através do

1. Trabalho realizado na disciplina Teoria Geral do Direito Privado, sob a orientaçăo da Professora Doutora Judith MartinsCosta.

2. A comissáo que elaborou o projeto de Código Civil foi coordenada pelo Professor Miguel Reale e era composta também por José Carlos Moreira Alves, Agostinho de Arruda Alvim, Sylvio Marcondes, Ebert Vianna Chamoun $\Theta$ Torquato Castro. Tratava-se do Projeto de Lei $n^{2} 634 / 75$ no Senado Castro. T
Federal. 
tempo graças à utilização da técnica conhecida como cláusulas gerais, que consiste, sob o enfoque da técnica legislativa,

uma disposição normativa que utiliza, no seu enunciado, uma linguagem de tessitura intencionalmente "aberta", "fluída" ou "vaga", caracterizando-se pela ampla extensão do seu campo semântico, a qual é dirigida ao juiz de modo a conferir-lhe um mandato (ou competência) para que, à vista dos casos con cretos, crie, complete ou desenvolva normas jurídicas, mediante o reenvio para elementos cuja concretização pode estar fora do sistema; estes elementos, contudo, fundamentarão a decisão, motivo pelo qual, reiterados no tempo os fundamentos da decisão, será viabilizada a ressistematização destes ele mentos originariamente extra-sistemáticas no interior do ordenamento jurídico, ${ }^{3,4}$

Surpreende, contudo, que a imprensa nacional, ao divulgar a tão esperada votação, tenha concentrado sua cobertura, exclusivamente, em aspectos meramente formais e superficiais do projeto. Questões de pura terminologia e redação, já há muito superadas pela prática forense, pela jurisprudência e, sobretudo, pela nova ordem constitucional instaurada em 1988, ofuscaram o conjunto de técnicas legislativas e opções doutrinárias, que tornam valioso o projeto.

O Senador Josephat Marinho Relator-Geral do Projeto no Senado - expressa com clareza a questão subjacente ao advento de um novo código, qual seja, a de decidir pela manutenção de um sistema codificado e de discernir que modelo de codificação é adequado ao tempo presente. $^{5}$

3. Para melhor conhecimento da obra do Professor Clóvis do Couto e Silva, consulte-se o obituário elaborado pelas professoras Judith Hofmeister Martins Costa e Vera Maria de Fradera, publicada na Revista de Direito do Consumidor, São Paulo, $n^{2} 3$, setembro/dezembro de 1992, da qual retiramos, exemplificamente, o seguinte extrato de sua obra: $A$ obrigação como processo, José Bushatsky Editor, São Paulo, 1976; Comentários ao Código de Processo Civil, volume XII, Tomos I e III, Revista dos Tribunais, São Paulo, 1977 e 1982, respectivamente; Les Principes Fondamentaux de la Responsabilité en Droit Brésillien et Comparé - Cours Fait à la Faculté de Droit et de Sciences Politiques de St. Maur, 1988. Weltwirtschafsordinung: Die Christliche Alternative zum Marximus, Ed. Union de Fribourg Institut International de Sciences Politiques et Sociales, Bonn, 1973; Legal Orders del X Congreso Mundial Ordinario de Filosofia del Derecho y Filosofia Social, vol. II, Ed. Universidad Autónoma de México, 1982; O principio da Boa-fé no Direito Civil Brasileiro e Português, in Estudos de Direito Civil Brasileiro e Português, RT, São Paulo, 1980; O Direito Civil Brasileiro em Perspectiva Histórica e Visão de Futuro, in RT 628/7 e Ajuris 40; Les Groupes de Societés, in Revue Internationale de Droit Comparé, Paris, 1990; Para uma História dos Pensamentos de Otto Karlowa e de Oskar Bullow, in Revista de Processo, volume 37, São Paulo; O conceito de empresa no Direito brasileiro, in Revista Ajuris, vol. 37, Porto Alegre; A Teoria da Base do Negócio Jurídico no Direito Brasileiro, in RT 655/7; Miguel Reale, Civilista, in RT 672/53; O conceito de Dano no Direito Brasileiro e Comparado, in RT 667ח; O princípio da Boa-fé e as condiçöes gerais dos negócios, in Condiç̧öes Gerais dos Contratos Bancários e a Ordem Pública Econômica, Coleção Anais Jurídicos, Curitiba, 1988. Recente coleçăo lançada pela Livraria e Editora do Advogado de Porto Alegre, Rio Grande do Sul, recupera artigos do autor. Trata-se da coletânea $O$ direito privado brasileiro na visão de Clóvis do Couto e Silva, organizado pela Professora Vera Maria Fradera, 1997.

4. Judith Hofmeister Martins Costa. Sistema e cláusula geral: A boa-fé objetiva no processo obrigacional, tese inédita de doutoramento em Direito Civil, Universidade de São Paulo, $1^{2}$ e $2^{2}$ volumes, 1996, citação da página 370 do $1^{2}$ volume. Sobre cláusulas gerais, ver por todos: Karl Engisch, Introdução ao pensamento jurídico. Tradução de J. Baptista Machado, Fundação Calouste Gulbenkian, 1993; Franz Canaris, Pensamento sistemático e conceito de sistema na ciência do Direito, Lisboa, Fundação Calouste Gulbenkian, 1989; e Judith Hofmeister Martins Costa, "As cláusulas gerais como fatores de mobilidade do sistema jurídico", Revista dos Tribunais, volume 680, páginas $47 / 58$.

5. Senador Josephat Marinho, Parecer final do Projeto de Código Civil, página do Senado Federal na Internet: http:// www.senado.gov.br.

Revista da Faculdade de Direito da UFRGS, v. 15, 1998
Para adequado entendimento desta exposição é preciso que se compreenda o Direito não como um mero conjunto de regras normativas, desvinculadas, independentes e soltas no espaço. Há que se entendê-lo, ao contrário, como um sistema, vale dizer: como um método de organização ou de ordenação. ${ }^{6}$ Não há que se confundir a idéia de sistema jurídico com a de ordenamento jurídico, haja vista que o primeiro exprime as relações, nem sempre existentes, entre as diversas normas que compõem o segundo; o ordenamento é uma espécie de ecossistema que pode abranger uma grande variedade de sistemas e subsistemas normativos. ${ }^{7}$ Sistema, portanto, quer significar também para o Direito conjunto, ordem, coerência e unidade. ${ }^{8}$

Nesta perspectiva queremos caracterizar o Direito como um sistema específico, um sistema de valores. Raul Mugaburu diz que o Direito é um sistema de valorações predominante ná sociedade e imposto pelo Estado com caráter público e geral e cuja aplicação, necessariamente obrigatória, regra a ação social para garantia do fim comum da comunidade. ${ }^{9}$ Temos, portanto, uma definição do sistema jurídico como um sistema mais filosófico do que propriamente jurídico. $\mathrm{Da}$ idéia de sistema como um conjunto de valores resulta a conseqüência lógica que são

estes valores que traçam o perfil do sistema jurídico e suas conexões internas e externas. Os valores servem, assim, como elos da corrente que compõem o ordenamento jurídico. ${ }^{10}$

Além da Constituição Federal e do Código Civil, vigem exemplificativamente, em matéria de Direito de Família, a Lei do Divórcio, com todas as suas alterações posteriores (Lei no 6.515/77), o Estatuto da Criança e do Adolescente (Lei no 8.078/ $90)$, o texto normativo que estabelece parâmetros para a investigação ou reconhecimento da paternidade (Lei no 8.560/92), a Lei que regula o direito dos companheiros a alimentos e à sucessão (Lei nº 8.971/ 94), sem deixar de mencionar também o diploma legal que regulamenta o $\S 3^{\circ}$ do artigo 226 da Constituição Federal - Lei da União Estável (Lei no 9.278/96). Resta, assim, ao aplicador do Direito operar em um emaranhado disperso e confuso de normas, contendo muitas vezes disposições de natureza substantiva e adjetiva, permissivo de antinomias e perplexidades interpretativas. Evidencia-se, desta forma, a ausência de um nexo, de um liame que reúna a todos estes diplomas e lhe empreste a coerência de um sistema. Carece, portanto, o Direito de Família daquilo que o Professor Clóvis chamou de unidade valorativa e conceitual,

6. Judith Hofmeister Martins Costa, Sistema e Cláusula Geral, ob. cit., página 40 .

7. Ibidem, página 41

8. Ibidem, página 39

9. Tradução livre do texto do Professor Raul Mugaburu, Esquemas sobre la sistematica del derecho (schemi sulla sistematica del dirito), Univeristá di La Plata, s.d., mar. 1952, p. 438, apud Revista di Diritto Civile, 1956

10. Odireito como sistema de valores é um enfoque típico de autores como Canaris, Pensamento sistemático e conceito de sistema na ciência do Direito, Lisboa, Fundação Calouste Gulbenkian, 1989. Também Hermann Eicheler in "Codificaçăo do Direito Civil e teoria dos sistemas de Direito", publicado na Revista de Direito civil, imobiliário, agrário e empresarial, Revista dos Tribunais, n? 2, páginas 43/57, outubro/dezembro de 1977; e ainda Raul Mugaburu, Esquemas sobre la sistematica del derecho (schemi sulla sistematica del diritto), ob. cit. 
ou seja, de um núcleo valorativo e uma técnica comum no Código Civil e nas leis especiais. ${ }^{11}$

Perceba-se que, quando do início da vigência do atual Código Civil, essa unidade valorativa no Direito de Família era realizada pelo próprio conceito de poder marital. ${ }^{12} \mathrm{O}$ feixe de direitos (e de obrigações) no qual consistia o poder do marido sobre toda a família representava a unidade do sistema legal familiar. Essa realidade tem origem remota. No dizer do Professor Cláudio de Cicco, a Revolução Francesa partiu da defesa da liberdade, para num segundo momento suprimi-la em nome da igualdade. ${ }^{13}$ Se na ordem política Napoleão praticamente negava os ideais abstratos da Revolução, assim também o código na ordem privada. O Code de Napoleão, o qual influenciou decisivamente no projeto elaborado por Clóvis Beviláqua, concebia um pátrio poder que significava o poder absoluto do marido e o direito do pai sobre o filho e sobre toda família. ${ }^{14}$

O alvorecer, entretanto, do princípio da igualdade iluminando o ordenamento jurídico, seja pela via jurisprudencial, dou- trinária ou legal, determinou o fim deste modelo de poder marital absoluto. $\mathrm{O}$ homem e seus interesses deixam de ser o núcleo do Direito de Família e também a mulher (Estatuto da Mulher Casada, Lei no 4.121/62) e os filhos (Estatuto da Criança e do Adolescente, Lei no 8.069/90) passam a ser plenamente sujeitos de direito e a merecerem regramentos jurídicos específicos. Reconhece-se a não-igualdade real entre eles, o que determina a criação de normas jurídicas próprias para regular os microuniversos jurídicos no qual estão inseridos estes novos sujeitos. Entretanto, a criação destes microssistemas jurídicos se dá de forma assistemática, não havendo eixos de ligação ou mesmo um sistema central que empreste subsídios uniformes a toda a estrutura.

A manifestada assistematização que restou demonstrada propõe aos operadores do Direito grande inquietação. Qual a solução? Restaurar as ruínas do Código Civil, como um sistema fechado, absoluto em si mesmo, onde se pretenda encontrar todas as soluções para todos os problemas do hoje e do porvir? Ou, como sugere o Professor Haroldo Valladão, instituir um código pró-

11. Tal perspectiva foi evidenciada no artigo "O direito civil brasileiro em perspectiva histórica e visão de futuro", Ajuris 40, 1987, transcrição de conferências que o autor realizou na Europa.

12. Segundo Carlos Silveira Noronha (Separata da Revista Forense, volume 326) em "Conceito e fundamentos de familia e sua evolução na ordem jurídica": O pater familias, que unificava sob sua auctoritas todos os membros da famillia, desirutava em relaçáo a eles de direitos de ordem pessoal e de ordem patrimonial, tais como a patria potestas ou o poder sobre os filhos e netos masculinos; a manus ou o poder sobre as mulheres casadas com o pater ou com seus descendentes; o mancipium ou o poder sobre as pessoas a ele vendidas como escravos (in mancipl): $e$ ainda a domica potestas, que era o poder geral sobre os escravos. Sobre os seus descendentes ou fillif familias, o poder tinha o ius vendendie o ius noxae dandi, ou seja, sobpecos escravos. Sobre os seus descendentes ou Mil Tamilas, o poder tinha o ius vendendi e o ius noxae dandi, ou seja, respectivamente, os direitos de vida e de morte; de abandonar o fiho infante, de vender as pessoas sob o seu poder; de livrar-se do filho

13. Cláudio de Cicco, Direito, tradição e modernidade, poder e autoridade na famflia e no Estado. Das origens romanas ao direito brasileiro moderno. Coleção Elementos do Direito, lcone Editora, Campinas, São Paulo, 1993, página 142.

14. Em artigo publicado na revista da Faculdade de Direito da USP, volume 88, 1993, e intitulado Breve histórico sobre o direito de familia nos últimos 100 anos, o Professor Silvio Rodrigues assevera que nas Ordenaçōes (Liv. V. Tit. 326, parágrafo $1^{2}$ ) o regramento entendia năo ser passivel de censura aquele que castigasse criado, ou discipulo, ou sua muther ou seu filho ou seu escravo.

Revista da Faculdade de Direito da UFRGS, v. 15, 1998 prio apenas para o Direito de Família e Sucessões, na pretensão de esgotar toda a possibilidade de hipóteses jurídicas? ${ }^{15}$ Talvez, embora sem tanto ceticismo, seguirmos a caminho dos microssistemas, como enfatiza Orlando Gomes? ${ }^{16}$ Mas que mode lo de microssistemas será este e que relação estabelecerá com um virtual eixo central?

Desde já quero adiantar que as res postas para estas questões estão em construção e não serão encontradas neste trabalho. Pretendo apenas compartilhar as dúvidas e questionamentos.

Na primeira parte, examinaremos a estrutura do Direito de Família conforme disposto no Projeto de Código Civil

Na segunda parte, tentaremos identificar alguns elementos viabilizadores de uma nova concepção de Direito de Família, organizado como um sistema orgânico e coeso, informado por valores comuns.

\section{Parte I. Estrutura do Direito de Família no Projeto do Código Civil}

Antes de iniciarmos o estudo da es. trutura inovadora que o Projeto de Código Civil empresta ao Direito de Família, é interessante que examinemos as diretrizes perseguidas pela Comissão que o elaborou:

- a primeira é a diretriz sistemática: o Código precisa ter uma unidade sistemática.

15. Haroldo Valladáo em O Direito Civil, o Código Civil Brasileiro e o Projeto de sua Reforma, Revista de Informaçăo Legislativa, $n^{2}$

16. Orlando Gomes in "A caminho dos micros-sistemas" (sic), Estudos jurídicos em homenagem ao Professor Caio Mário, Forense, Rio de Janeiro, 1984.

17. Miguel Reale, O Projeto de Código Civil, Editora Saraiva, 1986

18. Marcos Bernardes de Mello, Teoria do Fato Jurídico, Editora Saraiva, 1994.
- Em seguida, temos a eticidade manifestada raramente no atual Código Civil de postura individualista, consistente em exigências de ordem moral a que o le gislador atribui ao operador do Direito, no caso concreto, a sua concreção.

- Levou em conta também a inci dência dos valores sociais sobre os jurídi cos.

- E por fim, a operabilidade que visa à efetiva aplicação do Direito na vida as pessoas. ${ }^{17}$

\section{A. Direito Pessoal e Patrimonial de Família}

Dito isso, quero dizer que nem sempre o óbvio é tão óbvio. E há vezes nas quais afirmar o óbvio significa justamente rasgar concepções arraigadas, perenes, com status de verdades postas e inatingíveis.

Neste sentido, parece-nos bastante óbvio afirmar que a essência do direito é relação. ${ }^{18}$ Aliás, é notório também que o Direito, enquanto fenômeno, somente acontece onde puder ocorrer relação entre pessoas, entre pessoas e bens, e assim por diante. É, portanto, nas relações jurídicas que o cientista jurídico depara-se com o objeto da sua ciência, e fixa o laboratório do seu conhecimento.

Apesar desta obviedade, tem sido prática comum do legislador normar o $\mathrm{Di}$ -

Revista da Faculdade de Direito da UFRGS, v. 15, 1998 
reito de Família na forma de institutos jurídicos, não privilegiando com maior atenção as relações jurídicas que os compõem. Esta classificação os organiza de forma estanque, sem comunicação com os demais institutos e nem com as relações jurídicas que lhe são integrantes. Nesse teor, o casamento, a filiação e o parentesco, por exemplo, passam a ser vistos como fenômenos distintos e não relacionados entre si. As relações jurídicas que integram os institutos são percebidas de forma indireta, como por um espelho, sob foco nem sempre adequado. Afasta-se, nessa óptica, a possibilidade de analisar objetivamente os tipos de relações jurídicas, suas peculiaridades e as interpenetrações recíprocas que elas estabelecem.

Relevante, neste sentido, a contribuição de Clóvis do Couto e Silva ao segmentar o livro de Direito de Família no Projeto de Código Civil em duas grandes e inovadoras seções: direito pessoal de família e direito patrimonial de família. Esse critério leva em conta que nas relações de família existe em vínculo de natureza moral, jurisdicializado apenas parcialmente, e outro vínculo de natureza patrimonial, uma relação econômica, sem a qual seria impossível a manutenção do status de família.

Visualizam-se, assim, claramente, relações jurídicas de direito pessoal e relações jurídicas de direito patrimonial, anteriormente ofuscadas pela sombra que os enormes institutos faziam sobre as relações jurídicas. Esse corte epistemológico é vital, porque é da natureza da relação jurídica que

iremos extrair os efeitos jurídicos, as condutas e os papéis que os figurantes das relações irão realizar.

É de se notar que talvez, em nenhum outro ramo do Direito, esse eclipse era tão expressivo. ${ }^{19}$ Talvez, em nenhuma outra parte do Direito Positivo, os institutos carreguem no seu bojo tão grande carga de relações de natureza diversa.

Por exemplo, recuperemos os institutos do casamento, da filiação e do parentesco. Cada um desses institutos é depositário concomitantemente de relações distintas de natureza pessoal e de natureza patrimonial. No entanto, se fixarmo-nos apenas no instituto, aplicaremos às relações jurídicas lá embutidas uma leitura uniforme, ignorando e massificando as peculiaridades e - diria mais - as potencialidades das relações jurídicas que eles contêm.

Miguel Reale, com razão, defende que o Direito é social em sua origem e em seu destino, impondo a correlação concreta e dinâmica dos valores coletivos com os individuais, para que a pessoa humana seja sempre preservada. Ora, a perspectiva reducionista de classificar o Direito de Família como uma unidade completa, diluída em institutos estanques, consegue o seu pior resultado ao não reconhecer que no mundo dos fatos a mesma pessoa assume vários papéis sociais. Ora, se é pai, ora se é filho, ora se é irmão, profissional, religioso, e assim por diante. Também ao Direito, e sobretudo ao Direito de Família, cabe

19. Utilizo esta expressão para mero efeito didático. Acerca da ausência da dicotomia entre direito público e privado, consultar Ludwig Raiser, "O futuro do direito privado", Revista da Procuradoria-Geral do Estado, Porto Alegre, v. 9, n² 25, página 17, 1979.

Revista da Faculdade de Direito da UFRGS, v. 15, 1998 reconhecer que ora se é pessoa - titular de direitos específicos oriundos da relação matrimonial e familiar, e ora se é proprietário ou administrador de bens próprios, da comunhão que se estabeleceu ou pertencentes a seus filhos.

No entanto, trata-se sempre da mesma pessoa, que simplesmente assume diversos papéis não havendo por que segmentar de forma absoluta, o indivíduo enquanto membro do núcleo familiar ou enquanto proprietário de certos bens. ${ }^{20}$ Ao contrário, os conceitos devem interagir, naquilo que o Professor Miguel Reale chama de dialética da complementaridade:

as regras jurídicas se desenvolvem na experiência histórica também como resultado da complementaridade essen cial e inseparável entre a experiência jurídica pré-categorial e a experiência jurídica cientificamente ordenada, numa contínua interpenetração de influências, sem a qual não se abrange o comple xo mundo do Direito (grifo nosso). ${ }^{21}$

O projeto adota, assim, uma visão realística e plena do fenômeno familiar. $\mathrm{O}$ ente familiar não é exclusivamente uma reunião de afetos ou de patrimônios, mas o resultado da interação dinâmica destes dois componentes, juridicamente regrados. $\mathrm{Ou}$ tra não poderia ser a opção legal para que se estabeleça um liame efetivo entre a norma, o fato e o valor:

então o Direito não é um fato que plana na abstração, ou seja, solto no es paço e no tempo, porque também está imerso na vida humana, que é um com plexo de sentimentos e estimativas. O Direito é uma dimensão da vida huma na. O Direito acontece no seio da vida humana. ${ }^{22}$

A distinção proposta no Projeto tem, portanto, o mérito de reconhecer a existência de dois universos de relações jurídicas pessoais e patrimoniais -, permitindo que se dispense a elas tratamento adequado. ${ }^{23}$

No direito pessoal de família - reside a maior especificidade. As relações ciramoldam ao conceito clássico e hoje já desgastado de Direito subjetivo. Vejamos o tação - permeados de profunda pessoalidade e - acrescentaria - de profunda intimidade. Com razão Clóvis do Couto e Silva alerta que, na classificação das relações íntimas familiares, não haveria como enquadrá-las no conceito clássico de Direito subjetivo, ou ainda, ilusoriamente, tentar adequá-las a outros tipos de classificação que abstraíssem a titularidade destas relações. ${ }^{24}$ Vale dizer: a mulher não possui um cunscritas no núcleo familiar não se exemplo dos deveres de fidelidade e coabi-

20. Clóvis do Couto e Silva, "Temas atuais do Direito de Família no anteprojeto do Código Civil", cópia de palestra proferida no Instituto dos Advogados de São Paulo, em 07 de março de 1973. Biblioteca da Faculdade de Direito da UFRGS.

21. Miguel Reale, Teoria Tridimensional do Direito, Editora Saraiva, página 105, 1986. Consultar também o Direito como experiência São Paulo, $2^{\mathrm{a}}$ ediçāo, Saraiva, 1992

22. Miguel Reale, "Linha evolutiva da teoria tridimensional do Direito", Revista da Faculdade de Direito de São Paulo, volume 88, 1993.

23. Deparei-me com duas diversas redaçōes do Projeto de Código Civil: a redação final de 1975 e da Subsecretaria de Ediçōes Técnicas do Senado Federal, Brasilia, datada de 1989, aparentemente mais atualizada. Para efeitos didáticos, năo utilizarei a numeraçáo que os artigos citados adotam no conjunto do Projeto ou no livro de Direito de Família.

24. Clóvis do Couto e Silva, "Direito patrimonial de familia no projeto do Código Civil brasileiro e português", Revista dos Tribunais, volume 520 , página 14, 1979 
"crédito" sobre a fidelidade e a amorosidade do marido e vice-versa. Não é pertinente, também, falar-se que as relações marido/ esposa são direitos vinculados, direitos-deveres ou direito-função.

Sob a égide desta nova óptica, que valoriza a dialeticidade entre as relaçōes, encontrariam-se classificadas dentro do direito pessoal de família o casamento, as relações de parentesco, a adoção e o pátrio poder. Neste primeiro título do livro estariam as normas que incidem de forma dialética sobre o fato e o valor afeto. Ultrapassado o momento histórico da elaboração do Código Civil brasileiro, no qual a família tinha mera função de reprodução, sustento e educação dos filhos, passa-se ao período atual, no qual, um casal se une para buscar a felicidade através de relações de afeição e solidariedade que significam os pilares $d a$ família modema. ${ }^{25}$ Após a aprovação da Lei do Divórcio, o projeto foi alterado para estabelecer o princípio da igualdade entre homens e mulheres, também no direito pessoal de família, não havendo mais a ligeira supremacia marital que o modelo original pretendia, e que apenas facultava à mulher, em se tratando de questões essenciais e não personalíssimas, a petição judicial para tentar fazer valer sua posição divergente do marido.

No que concerne ao direito patrimonial de família, resta dizer que a ele são destinados aqueles institutos que não sofrem de forma tão aguda a carga ética das relações pessoais. Sendo regulados sob a forma do direito das obrigações ou das coisas, não perdem, contudo, a informação dos princípios de Direito de Família. O Professor Clóvis explica que eles permanecem matizados com os princípios próprios do Direito de Família. ${ }^{26}$

Entre o rol de inovações advindos pelo projeto, resta comentar sobre a idéia de administração. Essa idéia - entendo decorre de dois fatores principais: o primeiro é justamente a quebra do absolutismo marital no seio familiar. Já a primeira versão do então Anteprojeto de Código Civil instituía a igualdade plena dos cônjuges em questões patrimoniais. $O$ projeto conservou, todavia, a permanência do usufruto dos bens dos filhos pelos pais, mas agora com a diretiva de que estes devem administrá-los no interesse dos filhos e não no seu próprio. ${ }^{27}$ Outra não poderia ser atualmente a orientação, até mesmo em face dos princípios constitucionais vigentes e do microssistema estabelecido pelo Estatuto da Criança e do Adolescente (Lei 8.078/90). O segundo fator resulta da complexidade da vida moderna e do mundo econômico, tornando nem sempre viável ao mero mortal estar a par de todos os fluxos e refluxos negociais, o que lhe tornaria inapto para a administração dos bens. Faculta-se, assim a contratação de um terceiro para o fazer. ${ }^{28}$

25. Maria Claudia Crespo Brauner, "Consideraçōes sobre a filiaçăo extramatrimonial em Direito de familia francês e brasileiro", Revista de Informação Legislativa, Brasilia, Senado Federal, a. 33, no 129, março de 1996.

26. Ibidem, página 15.

27. Esta é inclusive a conotação de administração que permeia a Lei das Sociedades Anônimas (Lei nº 6.404/76), uma administraçăo realizada em proveito dos demais.

28. Na redação de 1989 , o primeiro artigo do subtítulo III - Da administraçáo dos bens de filhos menores - inserido no Capítulo VI do Título II - Direito patrimonial de familia: O paie a mãe são os administradores legais dos bens dos filhos menores que se achem em seu poder.

Revista da Faculdade de Direito da UFRGS, v. 15, 1998
Relacionados ao direito patrimonial de família, estariam o regime de bens, o usufruto, a administração dos bens dos filhos menores e o bem de família. Também estão aqui os alimentos, enquanto prestação devida, já que a classificação se dá tendo em conta a estrutura jurídica das relações e a prestação de alimentos apresenta-se como uma obrigação. Em título próprio estão a curatela e a tutela. ${ }^{29}$

\section{B. A Cláusula Geral da Comunhão Plena de Vida e Suas Repercussões}

A distinção entre direito pessoal e patrimonial de família, embora represente um grande avanço no sentido de pinçar as relações jurídicas que se escondiam por entre os institutos, de pouca valia teria, se o projeto não permitisse igualmente uma nova leitura destas relações. Uma leitura para além de todo o mofo que os códigos costumam acumular e de todo o envelhecimento que torna amarelado o papel e as idéias pelas quais foram escritos. Essa nova leitura das relações passa a ser feita pela inserção no projeto da cláusula geral da comunhâo plena de vida, a qual será o segundo grande enfoque ainda da primeira parte desta exposição.
O exemplo clássico de utilização de cláusula geral encontra-se na legislação alemã, nos parágrafos 242 e 826 do BGB, através dos quais insere-se o princípio da boa-fé e dos bons costumes. ${ }^{30}$

A cláusula geral da comunhão plena de vida implementada no Projeto do Código Civil é conceito ético, operativo, com conteúdo não totalmente definido; estabeleceu-se uma "lacuna interna", a ser preenchida pelas normas resultantes de sua concreção. Essa "lacuna interna" deverá se constituir, para o Direito de Família, em disposição análoga à de outras "cláusulas gerais" de natureza ética, como a do $\$ 242$ do BGB, para o Direito das Obrigações. ${ }^{31}$ A redação da cláusula geral inserta no livro de Direito de Família tem o seguinte teor:

Art. $1^{\circ}$. O casamento estabelece comunhão plena de vida com base na igualdade dos cônjuges e institui a família. ${ }^{32}$

Engisch explica que as normas jurídicas são formadas por duas partes: ${ }^{33}$

Prótase - que contém os elementos do suporte fático a caracterizar a relação jurídica a ser abrangida pela norma;

29. Consiste o Título III do livro de Direito de Família, redaçăo de 1989.

30. Liane Boll Kimmich, As cláusulas gerais no sistema jurídico de direito privado, Trabalho acadêmico inédito, Mestrado em Direito da Universidade Federal do Rio Grande do Sul, página 7, 1996, tradução do BGB: $§ 242$. O devedor está obrigado a cumprir a
prestação como exige a boa-fé, com consideraçấo aos costumes do tráfego. (Prestaçăo de acordo com a lealdade e crençalboafe.)

$\S 826$. Aquele que, de modo repugnante, contra os costumes, causar prejuízo intencional a outrem, está obrigado a reparar o prejuízo. (Prejuizo intencional contrário aos costumes.)

31. Clóvis do Couto e Silva, "Direito patrimonial de família no projeto do Código Civil brasileiro e português", ob. ctt., página 20.

32. Redação publicada em 1989 , no texto divulgado no final de 1975 , consta: O casamento estabelece comunhão plena de vida, com base na igualdade dos cônjuges, e institui a familia legitima.

33. Engish, Introdução, ob. cit., página 55 
Apódose - que traz as conseqüências jurídicas.

Desfazendo-me da visão peculiar de Engisch, que vê na construção da cláusula geral vagueza apenas na hipótese (prótase) e não na atribuição da conseqüência (apódose), afirmo que o reenvio acontece - como explicam Judith Hofmeister Martins Costa, em sua tese de doutoramento na Universidade de São Paulo, e Liane Kimmich, em trabalho acadêmico - nas duas partes da norma, abrangendo ampla variedade de casos de regulação jurídica, possibilitando a reunião de grupos de casos através da criação jurisprudencial da norma abstrata a partir do caso concreto, im pondo-se a cláusula geral como verdadeira técnica legislativa. ${ }^{34}$

Vale dizer: a cláusula geral da comu nhão plena de vida é aberta, tanto na hipótese quanto na conseqüência jurídica. Afinal, neste exato instante, quem poderá determinar com exatidão o que é comunhão plena de vida?

Quem é capaz para estabelecer com precisão matemática os efeitos, desdobramentos e as repercussões deste conceito em todo o Direito de Família?

A permeabilidade oportunizada pela utilização desta cláusula geral, no sentido de relacionar o sistema jurídico, viabilizando a abertura da ordem jurídica a outros valores sociais ainda não apreendidos pelo $\mathrm{Di}$ -

reito. O sistema jurídico não permanece, desta forma, alheio e indiferente às flutuações valorativas, que ocorrem no meio social no qual está inserido. Abre-se, igual mente, o Direito enquanto ciência a outros setores do conhecimento humano, como a filosofia, a antropologia e a sociologia, por exemplo. ${ }^{35}$ A cláusula geral enseja igualmente uma salutar catalisação da mobilidade intra-sistêmica, facilitando as interações interpretativas entre os diversos diplomas legais que compõem o Direito de Família, como o Código Civil, a Constituição Federal e a Lei do Divórcio, entre outros.

A cláusula da comunhão plena remete a valores éticos - meta ou extrajurídicos - aos comportamentos sociais, aos costu mes de hoje e do futuro, e do tempo presente para o aplicador do Direito.

Clóvis do Couto e Silva afirma ter a cláusula da comunhão plena de vida a mes ma importância que a da boa-fé para o Direito em geral, sobretudo o das obrigações. Essa importância é justamente a de ressistematizar o Direito. ${ }^{36}$

O princípio da comunhão plena de vida solto no vácuo do ordenamento jurídico não possuiria o condão da fácil aplicação jurisprudencial. Capturado em uma cláusula geral, oportuniza a sua fácil aplicação pelo órgão julgador que

abstratiza através do reenvio aos tópicos e aos grupos de casos reunidos em

34. Liane Boll Kimmich, As cláusulas gerais no sistema jurídico de Direito Privado, ob. cit., página 9.

35. Náo se está aqui afrontando a teoria pura do direito de Hans Kelsen, ao contrário, a proposta do reconhecido autor era de escoimar a ciência jurídica da interpenetração de outras ciências apenas para efeitos metodológicos. Jamais Kelsen imaginou um sistema que pretendesse tornar o direito intolerante aos fluxos e refluxos do meio social no qual está inserido.

36. Clóvis do Couto e Silva, "Princípios para a reforma do Direito de Família", Arquivos do Ministério da Justiça, Rio de Janeiro, a. 32, no $115,1975$.

Revista da Faculdade de Direito da UFRGS, v. 15, 1998 função de possuírem semelhante ratio decidendi e decide, de modo que também a sua decisão possa enquadrar-se em grupos de casos existentes ou iniciar a formação de novos grupos ou tópicos. ${ }^{37}$

Segue a autora sua linha de raciocí- nio:

Assim, a cláusula geral é aplicada através do pensamento problemático/tópiteriores ao sistema, funcionando como o canal de comunicação do sistema jurídico os demais sistemas sociais. Há assim, através das cláusulas gerais, a possibilidade de solução para os mais variados problemas não regulados pelo legislador, de modo a atribui ao sistema jurídico a característica da ple nitude, sem ser fechado. ${ }^{38}$

No dizer de Clóvis do Couto e Silva, a cláusula geral é um conceito ético, operativo, com conteúdo não totalmente definido, consistindo em lacuna interna a ser preenchida pelas normas resultantes da concreção. ${ }^{39}$

A cláusula geral da comunhão plena de vida promove verdadeira revolução na maneira de se vislumbrar os institutos e relações jurídicas de Direito de Família. Acredito que seria exaustivo e pouco criativo elencar um grande número de situações em co, permitindo a inserção de elementos ex que a cláusula da comunhão plena de vida possa repercutir no Direito de Família. Bas taria dizer que o grande papel da cláusula geral será o de sintetizar e enriquecer os deveres mútuos dos cônjuges..$^{40}$

De qualquer forma, é claro na doutrina que o casamento gera direitos absolu tos ou relativos. Não é comum, entretanto, como alerta Clóvis do Couto e Silva, pernum bem absoluto. ${ }^{41}$

Assim o 2º artigo do livro de Direito de Família prevê que:

Art. $2^{2}$. A pessoa alguma, pública ou privada, é dado interferir na comunhão de vida, instituída pelo matrimônio. ${ }^{42}$

Este seria o atributo principal da co munhão de vida: a não-interferência.

Estão protegidos o casamento - seja ele o que for ou vier a ser - e as instituições e relações jurídicas que dele se originem de qualquer maquinação humana que venha a interferir em tudo que esta união social possa representar.

Mais especificamente, no que tange ao direito patrimonial de família, qualquer manobra jurídica de um cônjuge no senticeber que o próprio casamento consiste

\section{Liane Boll Kimmich, As cláusulas gerais no sistema jurídico de direito privado, ob. cit., página 18}

38. Ibidem, página 28

39. Clóvis do Couto e Silva, "Direito patrimonial de familia no projeto de Código Civil brasileiro e no direito português", ob. cit., página

40. Sintetizar e enriquecer. Sintetizar na medida que sua vagueza e concomitante amplitude dispensam a produção constante de novas normas assim que mudam os valores sociais; enriquecer, uma vez que somente a ocorrência dos casos concretos e a relação simultânea do pensamento sistemático e tópico permitem dimensionar toda a potencialidade de casos a serem resolvidos pela irradiação da cláusula geral da comunhão plena de vida.

41. Clóvis do Couto e Silva, "Princípios para a reforma do Direito de Família", ob. cit., página 10.

42. Redação divulgada em 1989. Na reforma original, de 1975, verbis. É defeso a qualquer pessoa, de direito público ou privado, interferir na comunhão de vida constituída pelo matrimônio. 
do de ludibriar ou prejudicar o outro, que ofenda à cláusula da comunhão plena de vida é passível de anulação. Usando de mais um exemplo do autor do projeto de Direito de Família, podemos imaginar o caso de um marido que aliena aos bens do casal unilateralmente, ferindo a base econômica da família. Sendo possível tal disposição em face do regime de bens adotado, manterse-ia a incolumidade do negócio perante terceiros em prejuízo da mulher. No entanto, a venda poderia ser anulada se ficasse evidenciada a vontade do marido de prejudicar a esposa, em face da comunhão plena de vida que estes estabeleceram. São de dimensões inimagináveis as repercussões advindas pela adoção da técnica da cláusula geral da comunhão plena de vida, uma vez que se permite enquadrar nesta concepção conceitos que venham ainda a ser formados pela sociedade, dispensando-se o aumento da tão desgastante inflação legislativa.

Vencida a primeira parte da exposição, resta-nos, no próximo momento, refletir sobre o novo modelo de família que se estabelece nos nossos dias.

\section{Parte II. Cisão e}

\section{Ressistematização do} Direito de Família

Embora, enquanto operadores do Direito, tenhamos estudado o Direito de Família por muito tempo, desde os bancos dos cursos de graduação, foram poucas as

vezes nas quais nos perguntamos sinceramente sobre qual conceito de família estamos trabalhando e com qual modelo de família temos manipulado? Qual o perfil da família no limiar do terceiro milênio? Que modelo jurídico de família é adequado ao modelo real de família?

No primeiro momento desta segunda parte, traremos rapidamente alguns componentes sociais que incidem sobre as relações de família e a resposta jurídica a estes fatos sociais. Em seguida, e por derradeiro, analisaremos a ligação do novo modelo jurídico proposto pelo projeto do Código Civil com os microssistemas de $\mathrm{Di}$ reito de Família.

\section{A. O Direito de Família Como um Modelo Aberto}

Em interessante artigo intitulado Desbiologização da Paternidade, João Batista Villela faz menção a urna nova família, que deixa de ser unidade de caráter econômico, social e religioso para se firmar como grupo de afetividade e companheirismo. ${ }^{43}$ Salienta ainda que a nova família é transportada de uma idade institucionalista para uma idade eudemonista.

A mera observação aos dados estatísticos dos órgãos estatais revela esse novo modelo familiar. ${ }^{44}$ Uma família que se condiciona à mudança de uma economia iminentemente agrícola para uma economia industrial e que perde a sua composição ampla para uma mais restrita. Esta 43. João Batista Villela, "Desbiologizaçáo da Paternidade", Revista da Faculdade de Direito da Universidade Federal de Minas
Gerais, $n^{2} 21$, de maio de 1979. Também Guilherme de Oliveira, "Sobre a verdade e a fiçăao no Direito de Família" no Boletim da Faculdade de Direito da Universidade de Coimbra, volume LI, 1975.

44. Consultar informaçóes no endereço eletrônico do Instituto Brasileiro de Geografia e Estatística: http://www.sidra.ibge.gov.br. Abandona-se a concepção de uma família extensa - no dizer do Professor Salvatore Puleo, da Universidade de Palermo, - e pas. sa-se a uma família mais restrita, nuclear, ou seja, a família conjugal. Entre nós, na maior parte das vezes, a família compõe-se exclusivamente da mulher e dos seus filhos, ausente o pai, ou marido, ou companheiro. Tamanha a relevância de tal situação que os imóveis adquiridos via programas esta tais de habitação popular passaram recentemente a ser inscritos no nome da mulher e não no do marido. São as famílias ditas monoparentais, onde a criança é mantida e educada por somente um dos genitores. ${ }^{46}$

No mesmo artigo, já citado, do Professor Salvatore Puleo, o mestre italiano afirma que a família nasce espontaneamente, por uma exigência natural e até espiritual, de modo que a família precedendo a organização estatal é pré-jurídica. A esta visão de cunho naturalista contrapõe-se outra, pelo ângulo da psicanálise, que concebe a família como uma estrutura psíquica. Tal interFerreira em Direito de Família e Psicanálise Ensaio para uma proposta interdisciplinar. ${ }^{47} \mathrm{~A}$ família seria uma estrutura cultural; não se constituindo da mera união de macho, fêmea e filhos. Diz o autor: A família é uma constatação também é feita pelos civilistas. ${ }^{45}$ pretação é exposta por Rodrigo da Cunha estruturação psíquica, onde cada membro tem um lugar definido; o lugar do pai, da mãe e com isto o lugar do filho, repita-se. Tanto é assim, uma questão de lugar, que um indivíduo biológico. $\mathrm{O}$ autor reafirma sua assertiva com o instituto da adoção, permitido e incentivado pelo Direito. Distingue a reunião de animais para a reunião de uma família, pois justamente faltar a passagem da natureza para a cultura

Se a família - seja qual ela for - é um elemento cultural, não podemos esquecer que estamos em tempos de pósmodernidade. Assim o fez, entre nós, o Professor Erik Jaime, Doutor Doutor h. c. (sic) da Universidade de Heidelberg da Alemanha, enfatizando características que entende serem próprias da cultura pós-moderna no Direito, quais sejam: o pluralismo, a comunicação, a narração (o retorno aos sentimentos) e a valorização dos direitos humanos. Não é oportunidade para aprofundarmos estas características, mas bastaria repetir que a família e o modelo jurídico de família sofrem fluxos e refluxos decisivos da pós-modernidade, adquirindo dentro ou fora do sistema elementos sociais e ideológicos que passam a incluir a argumentação e as decisões jurídicas. ${ }^{48}$ pode ocupar o lugar de pais, sem que seja o pai

45. Salvatore Puleo, "Família Natural", Revista de Dinitto Civil, Parte Prima, 1979.

46. Maria Claudia Crespo Brauner, "Consideraçōes sobre a filiação extramatrimonial em Direito de Família francês e brasileiro", ob cit, página 300. No mesmo sentido, recente publicação do Professor Eduardo de Oliveira Leite, Famílias monoparentais, Editora Revista dos Tribunais, 1997

47. Rodrigo da Cunha Pereira, "Direito de família e psicanálise", Revista de Direito Civil, $n^{2} 64$, abriljunho de 1993.

48. Direito patrimonial de família na pós-modemidade: ciclo de conferências promovido pelo Curso de Pós-Graduaçáo - Mestrado em Direito, da Faculdade de Direito da Universidade Federal do Rio Grande do Sul (UFRGS), setembro de 1996. Também Cláudia Lima Marques in Contratos de Time-sharing e a proteção dos consumidores: critica ao direito civil em tempos pósmodemos, trabalho apresentado no Seminário sobre Derecho y politica de consumo, organizado pelo Ministerio de Sanidad y

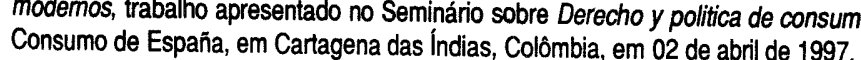

Revista da Faculdade de Direito da UFRGS, v. 15, 1998 
O impasse inicial que precisamos enfrentar para adequar a família fática à família jurídica é o da relação entre fontes do Direito e dos modelos de Direito.

O labirinto normativo estabelecido no chamado ancien régime, situado historicamente entre os séculos XVII e XVIII, permitia que a cada núcleo habitacional $e$ cultural da civilização ocidental fossem atribuídos foros de jurisdicidade aos usos e costumes locais. A tal situação juntava-se, ainda, o particularismo, ou seja, a possibilidade de existir regramentos jurídicos diversos e peculiares para determinados setores sociais, como o clero e os diversos níveis da nobreza. Neste quadro, as regras jurídicas variavam enormemente de cida de para cidade, e, em cada cidade, de uma "casta social" em relação às outras. Suponha-se, assim, o grau de incerteza e de insegurança jurídicas vivenciadas neste período. O Código Civil francês, proclamado em 1804, pretendeu justamente tornarse o direito comum de todos os cidadãos, eliminando a multiplicidade normativa e os privilégios específicos de certos membros da comunidade. A era da codificação instau rada a partir de então representa o mundo da segurança: iguala a todos sob o pressu posto comum da liberdade individual, fun damento da igualdade e bandeira da Revolução Francesa. Os códigos passam a ser a única fonte normativa válida, exclusi va e excludente, de forma a forjar justamen-

te uma sensação de certeza e segurança jurídica. ${ }^{49}$

Paolo Grossi, insigne professor italiano, conceitua este momento da história da evolução jurídica como la más colosal operación de política del derecho en todo el arco de la historia jurídica occidental, justamente porque representa a tomada de consciência da importância, pelo poder político, do que representa o controle jurídico da sociedade, e estabelece, a partir de então, sobre o último um forte monopólio. ${ }^{50} \mathrm{~A}$ ascendente classe burguesa vê na segurança fornecida pelo código o atendimento de seus mais altos interesses liberais e individualistas. $O$ código era, portanto, a fonte de produção jurídica por excelência.

Após 1918, inicia-se a constitucionalização das grandes demandas sociais e a construção do chamado Estado Social de Direito - o Welfare State - caracterizado pela intervenção estatal no planejamento da sociedade e do Direito privado. $O$ individualismo e o liberalismo concebidos na genesis do processo codificante cedem espaço. Ora, nessa nova conjuntura histórica, sentiu-se a necessidade de uma nova Dogmática Jurídica, revelando-se insuficiente uma solução redutível a meras regras hermenêuticas, ou à simples valorização desta ou daquela outra fonte tradicional: fortaleceuse em suma, cada vez mais, a exigência de repensamento e revisão das teorias das fontes do Direito (o grifo é nosso).$^{51}$

49. Aprofundem-se tais assertivas consultando Judith Hofmeister Martins Costa, Sistema e Cláusula Geral, ob. cit. e Danilo Knijnik Aprofundem-se tais assertivas consultando Judith Hormester Martenico inédito, Curso de Pós-Graduaçăa -Mestrado em Direito Codificação, descodificação e o papel dos códigos, trabalho acadêmico
UFRGS, Orientadora Judith Hofmeister Martins Costa, agosto de 1994.

50. Paolo Grossi, Absolutismo jurídico y derecho privado en el siglo XIX, Bella Terra, Universitat Autônoma de Barcelona, Barcelona 1991.

51. Miguel Reale, Da teoria das fontes à teoria dos modelos do Direito", Boletim da Faculdade de Direito da Universidade de Coimbra, volume LVIII, Portugal 1982

Revista da Faculdade de Direito da UFRGS, v. 15, 1998
Gostaria, entretanto, de convidá-los a voltarmo-nos para o futuro preocuparmo-nos com os modelos jurídicos. Sabemos pelo Professor Miguel Reale que as fontes são retrospectivas - voltando-se para a origem da norma, enquanto os modelos são prospectivos referindo-se a norma enquanto esta se atualiza, assumindo distintos valores semânticos, ainda que não ocorra qualquer mudança no seu enunciado verbal..$^{52}$ Os modelos jurídicos consistem, portanto, estrutura normativa que ordena fatos segundo valores, numa qualificação tipológica de comportamentos futuros, a que se ligam determinadas conseqüencias. ${ }^{53}$ Representam a lógica ou logicidade inerente as ordenações da conduta humana, e em assim dizendo, podemos identificar vários modelos jurídicos. No dizer ainda de Reale, cada modelo expressa, pois, uma ordenação lógica de meios afins, assim como o modelo arquitetônico é um projeto que antecipa e condiciona a constru ção de um edifício. ${ }^{54}$ Estruturam-se, justamente, a partir da integração dos fatos e valores segundo normas postas, em virtude de um ato concomitante de escolha e de prescrição, que poderá ser do legislador ou do juiz. ${ }^{55}$

Esclareça-se que um modelo jurídico pode ser construído por uma única regra de Direito, ou por um conjunto de regras interligadas. Não há que se confundir normas jurídicas e modelos jurídicos; ao modelo jurídico reputamos uma pluralidade de

normas entre si articuladas compondo um todo irredutível às suas partes componentes. A lei de Introdução ao Código Civil, por exemplo, pode, no seu todo, ser considerada um modelo jurídico, visto que é um complexo de regras diversas, correlacionadas entre si, em razão de um objetivo comum, que consiste em disciplinar diversas hipóteses de interpretação e aplicação da lei.56

Prossegue o coordenador da comissão que elaborou o projeto: Ressalta-se no Direito a idéia de planificação lógica e a re. presentação simbólica e antecipada dos resultados a serem alcançados por meio de uma seqüencia ordenada de medidas ou prescrições. ${ }^{57}$

Neste sentido, urge que tenhamos sensibilidade científica de perceber que os modelos jurídicos que servem ao Direito em geral, e ao Direito de Família de forma es. pecial, devem ser recuperados numa feliz expressão do Professor Reale das formas de viver concreto dos homens. Acrescenta ainda o ilustre supervisor da elaboração do projeto do Código Civil que na sociedade se constituem formas de vida, modos de com. portamento, que têm força de estruturas sociais obrigatórias: são fontes de direitos e seus modelos jurídicos, o Direito objetivo, em suma, que surge obedecendo à nature. za das coisas, às linhas evolutivas imanentes ao fato social e histórico (o grifo é nosso).$^{58}$

52. Miguel Reale, ibidem, página 795. Consultar também do mesmo autor $O$ Direito como experiência, ob. cit.

53. Miguel Reale, $O$ direito como experiência, ob. cit., página 162.

54. Miguel Reale, "Da teoria das fontes à teoria dos modelos do Direito", ob. cit., página 798.

55. Miguel Reale, $O$ direito como experiência, ob. cit., página 163.

56. Miguel Reale, Liçōes Preliminares de Direito, Saraiva, $18^{a}$ edição, 1991

57. Miguel Reale, "Da teoria das fontes à teoria dos modelos do Direito", ob. cit., página 798.

58. Ibidem, página 798 
No modelo de família contemporâneo, acima caracterizado, que em nada se assemelha ao do início do século, e que permanece em processo de mutação, seria um grave erro pretender restabelecer a criação de normas hermeticamente fechadas e dispostas a conterem em si todas as indagações e inquietações do hoje e do porvir. Neste diapasão segue o projeto de Código Civil ao estabelecer evidentemente um modelo jurídico aberto, ou seja, suscetível de permeabilidade com o meio social ao qual está inserido. ${ }^{59}$ Deve-se desde logo afastar a vaidade de pretender fazer um Código de Direito de Família que seja algo perfeito e ideal, porque semelhante código só poderia endereçar-se a uma sociedade com os mesmos predicamentos, ou seja, não teria nenhuma repercussão no mundo atual, e sobretudo na sociedade brasileira, em face de transição. ${ }^{60}$

Assim, constatado que o modelo jurídico adequado para a família seja um modelo aberto, resta-nos visualizar esta abertura em face do projeto de Código Civil com sua cláusula geral e dos microssistemas que compõem o Direito de Família. Trata-se do último item desta parte.

\section{B. Inter-relações Sistêmicas} podemos previamente constatar o sólido
No ponto no qual nos encontramos,

aparato teórico e instrumental fornecido pelo projeto de Código Civil ao Direito de Família. Tais concepções, como a de evidenciar - sem separar - as relações de direito pessoal e patrimonial, e a utilização da técnica das cláusulas gerais, arejam com ares permanentemente renovados a legislação brasileira. Da mesma forma, a compreensão do Direito como um sistema - e um sistema informado por valores sociais e a conseqüente organização de modelos jurídicos garantem atualidade à norma jurídica.

Ora, de nada nos serviria toda esta estrutura se permanecêssemos míopes. $\mathrm{Ne}$ cessário é, portanto, a utilização de novos óculos para contemplar e interagir com esta nova realidade.

O conceito de sistema que já enfrentamos supõe duas acepções: o sistema como uma unidade interna e como unidade externa.

Ao sistema interno corresponde a existência de laços imanentes de conexão sendo estes laços passiveis de articulação via operações dedutivas entre as diversas ordens de grandeza que o compõem (o grifo é nosso). ${ }^{61}$ No projeto de Código Civil, o liame que restabelece a unidade intrínseca ao sistema é a cláusula geral da comunhão plena de vida, que ocupa o papel de unidade

59. Esclareça-se, por oportuno, que a constituição de um modelo jurídico de familia denominado aberto refere-se, exclusivamente, à permeabilidade do meio jurídico às mutaç̋es sociais, sem querer induzir em nada a um modelo especfifico de ser familia. Ao contrário, o instrumental jurídico posto à disposição neste trabalho pretende valorizar a comunhão plena de vide como diretriz corteadora das rocios

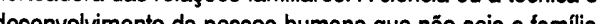

60. Clóvis do Couto e Silva, "Temas atuais do Direito de Família no anteprojeto do Código Civil", ob. cit., página 143. Penso que o autor faça menção a um código que pretenda estar pronto, ou seja, completo em suas próprias disposiçóes, insuscetivel de trocas com o meio, em face das mutaçóes valorativas que ocorrem no tecido social.

61. Judith Hofmeister Martins Costa, Sistema e cláusula geral, ob. cit. página 41.

Revista da Faculdade de Direito da UFRGS, v. 15, 1998 valorativa e conceitual..$^{62}$ A partir do conceito do que possa ser considerada a comunhão plena de vida, constrói-se a logicidade própria e inerente ao Direito de Família. A idéia de proteger e incentivar o estabelecimento da comunhão plena de vida no núcleo famili ar permeia a todo sistema jurídico interno tendo cada dispositivo legal sentido pleno a partir deste referencial.

No que concerne ao sistema enquanto unidade externa, ele consiste na exposição metodicamente ordenada da matéria jurídica. Significa, pois, a ordem através da qual vem exposto o resultado. ${ }^{63}$

Ao contrário do que se possa inicial mente pensar, a recodificação ou a elabora ção de um novo código não pretende em momento algum anular as legislações que se criaram ao longo do código e com que ele mantêm relações. Recodificação que significar, ao contrário, uma nova maneira de ver o código, não mais como um sistema fechado em si mesmo, completo, exclusivo e excludente, mas como um modelo aber to, suscetível de realizar trocas com o meio social.

A necessária conjugação e recíproca influência exercida pelos sistemas interno e externo são evidenciadas pelo novo enfoque jurídico advindo da codificação, na medida que

forma e conteúdo mantêm íntimas relações, ou no caso específico do fenôme. no, numa clara comprovação que o sistema interno pode influenciar o externo e viceversa; dai a relevância científico-dogmática do primeiro (os grifos são nossos). ${ }^{64}$

A unidade interna do sistema proje. ta-se para fora, vinculando todo o sistema externo.

A partir do Código Civil como eixo central do sistema de direito privado, orbitam as periferias estabelecidas pelos microssistemas. ${ }^{65} \mathrm{O}$ Código não é um elemento solto e desvinculado das demais leis supervenientes, mas, ao contrário, é a estrutura fundante ou fundamentante das leis especiais, porque nele estariam as pressuposições jurídicas (as amplas categorias jurídicas) necessárias à implementação das leis especiais. ${ }^{66}$ Nesta perspectiva é coerente a afirmação de Orlando Gomes de em nada adiantaria transformar o Código Civil em uma sede emprestada de microssistemas centrifugos. ${ }^{67}$

A Constituição Federal, o Estatuto da Criança e do Adolescente, a Lei da União Estável, entre outras normas jurídicas, estão como que costuradas pelo valor comum fixado no Código Civil. O valor representado pela comunhão plena de vida é comum e inerente a toda estrutura, seja na Constituição, no Estatuto da Criança e do Adolescente ou em outro texto normativo. A indiferença com que se relacionavam estas

62. Clóvis do Couto e Silva, "O direito civil em perspectiva histórica e visãa do futuro", ob. cit.

63. Judith Hofmeister Martins Costa, Sistema e cláusula geral, ob. cit., página 41

64. Danilo Knijnik, Codificação, descodificação e o papel dos códigos, ob. cit., página 58.

65. A expressão eixo central é da autoria do Professor Clovis do Couto e Silva. Conferir a obra já citada, "O direito civil brasileiro em perspectiva histórica e visão de futuro".

66. Natalino Irti, "Leggi speciali - dal mono-sistema al poli-sistema", Revista de Diritto Civile, Parte Prima, 1979

67. Orlando Gomes in "A caminho dos micros-sistemas" (sic), ob. cit., página 167.

Revista da Faculdade de Direito da UFRGS, v. 15, 1998 
normas, portadoras de per se de seus pressupostos particulares, é substituída por um critério comum, superando as divergências interpretativas, o surgimento de antinomias e a prolação de decisões judiciais diversas para o mesmo tipo de situação jurídica.

\section{Apontamentos Conclusivos}

Com razão afirmou Roberto Vieira que o Direito não é, está sendo. ${ }^{68}$ Neste sentido seria inútil trair as pretensões desta exposição e pretender tecer conclusões cabais e terminativas. Não nos furtamos, entretanto, de partilhar algumas de nossas anotações acerca do tema enfrentado:

a) o Direito deve ser concebido como um sistema orgânico, coerente e uno, cor respondente a um método de organização e ordenação;

b) este sistema, numa visão particular, consiste em um todo composto de valores culturais e sociais;

c) a perda do núcleo valorativo comum ao Direito de Família provocou a sua assistematização, deixando o Código Civil de ser o núcleo central do sistema de direito privado;

d) a alternativa ressistematizadora passa pela recuperação de unidade valorativa e conceitual que empreste harmonia ao sistema. Necessário dotar a estrutura de meios permanentes de renovação que permitam a permeabilidade do Direito aos valores externos;

e) a utilização das cláusulas gerais e o estabelecimento de modelos jurídicos abertos permitem a renovação do Direito, em meio à constante mutação dos valores sociais de nossos dias. Evitam-se igualmente o estímulo à crescente inflação legislativa e a conseqüente corrosão do valor da lei positivada. Prestigiam-se os valores da certeza e segurança jurídicas.

\section{Bibliografia}

Anteprojetos de Código Civil, Senado Federal, Subsecretaria de Ediçōes Técnicas, Brasília, 1989.

Brauner, Maria Claudia Crespo. Considerações sobre a filiação extramatrimonial em direito de família francês e brasileiro. Revista de Informação Legislativa, Brasília, Senado Federal, a. 33, no 129, março de 1996

Canaris, Claus Wilhelm. Pensamento sistemático e conceito de sistema na ciência do direito. Fundação Calouste Gulbenkian, Lisboa, 1989.

Couto e Silva, Clóvis. Direito patrimonial de família no projeto de Código Civil Brasileiro e no direito português, 1979.

Exposição de motivos do livro relativo ao direito de família no anteprojeto de Código Civil, 1975.

Direito patrimonial de família. Revista da Faculdade de Direito da UFRGS, 1971, no 1 .

Temas atuais do Direito de família no anteprojeto do Código Civil. Cópia de palestra proferida no Instituto dos Advogados de São Paulo, em 07 de março de 1973. Biblioteca da Faculdade de Direito da UFRGS 347.6 S586t.

68. Roberto Átila Amaral Vieira, "O Direito não é, está sendo", Revista de Informação Legislativa, a. 7, $\mathrm{n}^{\mathrm{Q}} 28$, outubro/dezembro, página 168,1970
O direito civil brasileiro em perspectiva histórica e visão de futuro. Ajuris 40, julho de 1987.

De Cicco, Cláudio. Direito, tradição e modernidade. Poder e autoridade na família e no estado. Das origens romanas ao direito brasileiro moderno. Coleção Elementos do Direito, Ícone Editora, Campinas, São Paulo, 1993.

Eicheler, Hermann. "Codificação do direito civil e teoria dos sistemas de direito". Revista de Direito civil, imobiliário, agrário e empresarial, Revista dos Tribunais, $\mathrm{n}$ 응 2, páginas, 43/57, outubro/dezembro de 1977.

Engisch, Karl. Introdução ao Pensamento Jurídico. Tradução J. Baptista Machado, 6a edição, Lisboa, Calouste Gulbenkian, 1983.

Ferreira, Roberto Schaan. "A influência de fatores metajurídicos no sistema de direito privado - modelo aberto externo". Revista de Informação Legislativa, a. 29, n 114, abril/junho de 1992.

Gomes, Orlando. A caminho dos microssistemas, in Estudos jurídicos em homenagem ao Prof. Caio Mário, Forense, Rio de Janeiro, 1984.

1 Grossi, Paolo. Absolutismo jurídico y derecho privado en el siglo XIX, Bella Terra, Universitat Autônoma de Barcelona, Barcelona, 1991.

Irti, Natalino. Leggi speciali - dal mono-sistema al poli-sistema. Revista de Diritto Civile, 1979, parte I.

Kimmich, Liane. As cláusulas gerais no sistema jurídico de Direito Privado. Trabalho acadêmico inédito, Mestrado em Direito UFRGS, Orientadora Judith Hofmeister Martins Costa, 1996.

Knijnik, Danilo. Codificação, descodificação e o papel dos códigos. Trabalho acadêmico inédito, Curso de Pós-Graduação Mestrado em Direito UFRGS, Orientadora Judith Hofmeister Martins Costa, agosto de 1994.

Leite, Eduardo de Oliveira. Famílias monoparentais, Editora Revista dos Tribunais, 1997.

Mello, Marcos Bernardes de. Teoria do Fato Jurídico, Editora Saraiva, 1994.

Martins Costa, Judith Hofmeister. "As cláusulas gerais como fatores de mobilidade do sistema jurídico". Revista dos Tribunais, volume 680, páginas 47/58, 1992.

"Clóvis do Couto e Silva: 1930 - 1992". Revista de Direito do Consumidor, São Paulo, no 3 , setembro/ dezembro de 1992.

. Sistema e cláusula geral: A boa-fé objetiva no processo obrigacional. Tese inédita. $1^{\circ}$ e $2^{\circ}$ volumes, 1996.

Magaburu, Raul. Esquemas sobre la sistematica del derecho (schemi sulla sistematica del diritto), Univeristá di La Plata, s.d., mar. 1952, pp. 438 apud Revista di Diritto Civile, 1956.

Noronha, Carlos Silveira. Conceito e fundamentos de família e sua evolução na ordem jurídica. Separata da Revista Forense, volume 326,199 .

Oliveira, Guilherme de. "Sobre a verdade e a ficção no direito da família". Boletim da Faculdade de Direito, Universidade de Coimbra, volume LI, 1975.

Pereira, Rodrigo da Cunha. "Direito de família e psicanálise". Revista de Direito Civil, abril/junho de 1993, no 64 .

Puleo, Salvatore. "Concetto di Famiglia e Rilevanza della Famiglia Naturale", Revista di Diritto Civile, 1979, Parte Prima. 